Bulletin d'Histoire Contemporaine de I'Espagne

$54 \mid 2020$

Les espaces du politique dans l'Espagne du Trienio liberal (1820-1823)

\title{
Rafael del Riego dans la poésie de circonstance du Triennat libéral
}

Rafael del Riego en la poesía de circunstancia del Trienio liberal

Rafael del Riego in the poetry of the occasion of the Liberal Triennate

\section{Gérard Dufour}

\section{OpenEdition}

\section{Journals}

Édition électronique

URL : http://journals.openedition.org/bhce/2288

DOI : $10.4000 /$ bhce.2288

ISSN : 1968-3723

\section{Éditeur}

Presses Universitaires de Provence

\section{Édition imprimée}

Date de publication : 1 janvier 2020

ISSN : 0987-4135

\section{Référence électronique}

Gérard Dufour, «Rafael del Riego dans la poésie de circonstance du Triennat libéral », Bulletin d'Histoire Contemporaine de l'Espagne [En ligne], 54 | 2020, mis en ligne le 01 juillet 2020, consulté le 03 janvier 2021. URL : http://journals.openedition.org/bhce/2288 ; DOI : https://doi.org/10.4000/bhce.2288

Ce document a été généré automatiquement le 3 janvier 2021.

Bulletin d'histoire contemporaine de l'Espagne 


\title{
Rafael del Riego dans la poésie de circonstance du Triennat libéral
}

\author{
Rafael del Riego en la poesía de circunstancia del Trienio liberal \\ Rafael del Riego in the poetry of the occasion of the Liberal Triennate
}

\section{Gérard Dufour}

1 Avec la seconde Révolution d'Espagne (pour employer l'expression de l'époque), la politique envahit tous les domaines : la presse, qui retrouve sa liberté, la prédication ${ }^{1}$, les beaux arts (sous forme essentiellement de gravures, les tableaux de maître non pas $\mathrm{du}$ pauvre, mais des classes moyennes), et les belles-lettres, dans toutes ses déclinaisons : théâtre, roman, histoire, essais et poésie. De nos jours, cette dernière est tenue pour un "sport cérébral ", pratiqué par de rares adeptes enfermés à triple tour dans leur tour d'ivoire. Comme me dit un jour, avec humour, lucidité et résignation, un collègue bolivien : « los poetas unidos, jamás serán leídos ». De fait, les tirages des quelques ouvrages de poésie que l'on publie aujourd'hui sont pitoyables. Mais il n'en a pas été toujours ainsi : nous avons déjà souligné la véritable fureur poétique qui régnait en France dans les années 1820 dans un article publié dans El Argonauta español. Nous nous permettrons donc d'y renvoyer ceux qui, d'aventure, seraient intéressés par le sujet ${ }^{2}$. Mais il en allait exactement de même en Espagne où, avant la Guerre d'Indépendance on crut bon, voire nécessaire, de donner une version versifiée d'une anthologie de sermons du P. Diego de Cádiz ${ }^{3}$ et, pendant le Triennat libéral -à l'instar de ce qui avait eu lieu en France avec la Charte octroyée ${ }^{4}$ - d'en faire tout autant avec les articles les plus importants de la Constitution de la monarchie espagnole proclamée à Cadix en $1812^{5}$.

2 En fait, nos ancêtres étaient persuadés, comme on put le lire dans Les Lettres champenoises, que «la prose s'envole et les vers restent $»^{6}$. Aussi tout événement d'importance (ou auquel on voulait conférer de l'importance) se devait-il d'être célébré sous forme d'odes, hymnes, sonnets et autres compositions répertoriées dans l'Art poétique. Bien entendu, dans la plupart des cas ces pièces relèvent davantage des bouts rimés que de la poésie et parmi ces prétendus poèmes on ne saurait compter les mauvais, les très mauvais, les très -très mauvais et les exécrables. Mais il est des 
exceptions, et on ne saurait oublier qu'en France, c'est grâce à cette poésie événementielle que Victor Hugo, avec Les Méditations, et Vigny, avec Le Trapiste (tantôt avec un seul « p ", tantôt avec deux) prirent place au premier rang des écrivains de leur temps et qu'il se trouvait en Espagne des poètes de la force d'un Quintana ou d'un Mor de Fuentes dans la péninsule, et d'un Heredia, à La Havane.

Toutefois, ce n'est pas la valeur littéraire de cette poésie de circonstance qui importe pour nous mais bien le fait que, en l'absence de ces sondages si chers à nos journalistes et politologues, elle nous permet de juger de l'impact d'un événement sur l'opinion publique et, pour ce qui concerne les acteurs du jeu politique et autres célébrités, de leur degré de popularité ou, au contraire, de l'exécration dont ils furent l'objet.

Force est de reconnaitre, toutefois, que cette mesure de l'opinion publique est loin d'avoir la précision d'une pesée sur un trébuchet d'orfèvre ou d'une balance de pharmacien. D'abord, bien de ces « petits impromptus préparés hier » et récités ou lus à l'occasion de quelque cérémonie officielle n'ont jamais eu l'honneur d'être imprimés ni même consignés dans un quelconque carnet. Ensuite, parce que, comme il se passe toujours lors que triomphent des forces réactionnaires, ceux qui avaient en leur possession des publications qui pouvaient être compromettantes s'empressèrent de les détruire quand ils virent que la cause du libéralisme était perdue et nous ne connaissons ainsi bon nombre d'ouvrages que par leurs annonces parues dans la presse. Quant à celle-ci, on ne dispose pour bon nombre des 680 périodiques recensés par Alberto Gil Novales dans ce qui est sans doute son chef-d'œuvre, Las Sociedades patrióticas... ${ }^{7}$, que des collections lacunaires, voire extrêmement lacunaires, et dans bien des cas, les seules indications que l'on possède sur un journal correspondent à des citations de celui-ci publiées par un confrère, quand, purement et simplement, on ne doit pas se contenter du titre du quotidien ou de la revue.

Autrement dit, quelle que soit l'ardeur du chercheur, sa quête des poèmes de circonstance composés pendant le Triennat libéral restera incomplète. Mais elle n'en sera pas pour autant inutile et, à notre sens, c'est, sinon le seul, du moins l'un des plus surs moyens d'améliorer notre connaissance de l'évolution de l'opinion publique au cours de cette période.

Nous ne sommes pas en mesure, aujourd'hui, de présenter autre chose qu'une étude de cas. Notre choix s'est porté sur les poèmes consacrés à Riego, le personnage le plus emblématique de la seconde Révolution d'Espagne qui, passant en quatre ans du pinacle à l'échafaud, constitue un cas paradigmatique de la versatilité de cette opinion publique que nous cherchons à mieux appréhender.

\section{Le corpus}

Nous avons donc pu constituer jusqu'à présent un corpus de 283 poèmes qui vantent ou vilipendent la personnalité de Riego et nous avons publié un certain nombre d'entre eux dans l'ouvrage paru sous le titre De ¡Viva Riegoooo! a jMuera Riego Antología poética (1820-1823)8. Ils vont, du point de vue du volume, du sonnet à des compositions d'une trentaine de pages. Six de ces textes avaient été publiés sous forme d'opuscules; huit dans des recueils d'hymnes ou chansons patriotiques et les autres dans la presse à l'exception d'une ode qui, restée manuscrite pendant le Triennat, fut livrée à l'appréciation du public une vingtaine d'années après qu'elle ait été écrite ainsi qu'un autre poème qui, à ce jour bénéficie d'une édition numérique. Mais il conviendrait de 
leur ajouter cinq titres qui furent annoncés dans les journaux de l'époque, mais qui ne figurent pas dans le catalogue de la Biblioteca Nacional de España et que je n'ai pu trouver sur le site de cette gigantesque bibliothèque que nous offre Google livres.

\section{Riego, Riego seul, et c'est assez}

8 On peut remarquer que Riego dispose, dans son entourage, d'un groupe de communicants (comme l'on dirait de nos jours) particulièrement zélés. D'abord, son frère, Miguel, chanoine de la cathédrale d'Oviedo, qui, peu après la proclamation de la Constitution à La Corogne rédigea une ode en l'honneur de "l'immortel Riego ", qui ne put être alors être publiée mais circula sans doute sous forme de manuscrit ${ }^{9}$. Mais c'est surtout au sein de l'armée de la Isla que le général rebelle compta ses plus efficaces propagandistes. Ainsi le capitaine Santiago Pérez, attaché au commandement général de la première division de l'Armée Nationale réunie en Andalousie, publia à Séville en 1820 un opuscule intitulé ¿Quién es el libertador de la España? dans lequel il affirmait sans ambages que seul Riego méritait le titre de libérateur de la Nation, excluant ainsi tout partage d'une telle gloire avec Quiroga ${ }^{10}$. Mais surtout, le lieutenant-colonel Evaristo Fernández de San Miguel composa à Algesiras, (donc entre le 31 janvier et le 7 février 1820), ce que l'on a coutume d'appeler l'Hymne de Riego mais dont le titre originel exact est celui d'Hymne du citoyen Riego (Himno del ciudadano Riego). En fait, il ne s'agit pas d'un hymne de Riego, mais à Riego, dont le caractère hagiographique et propagandistique ne fait aucun doute, puisqu'on y trouve les couplets suivants :

¿El mundo vio nunca

Tan noble osadía?

¿Lució nunca un día

Más grande en valor

Que aquel que inflamados

Nos vimos del fuego

Que existará en Riego

De Patria el amor

CORO

Soldados, la Patria...

SOLO

Honor al caudillo,

Honor al primero

Que el cívico acero

Osó fulminar.

La Patria afligida

Oyó sus acentos,

$\mathrm{Y}$ vio sus tormentos

En gozo tornar.

9 Les musicologues discutent pour savoir à qui attribuer la première version musicale de cet hymne qui servit de chant de marche à l'armée de Riego ${ }^{11}$. Mais ce qui est certain, c'est qu'il connut un incroyable succès (semblable à celui de notre Marseillaise tout au long du chemin qui mena nos fédérés jusqu'à Paris) au point que, dès le début du mois de mars 1820, le Diario Patriótico constitucional de la Coruña en publia le texte qui fut repris le 19 dans le Constitucional o sea crónica científica, literaria y política ${ }^{12}$ et que, deux 
ans plus tard, le 7 avril 1822, les Cortès proclamèrent l'hymne de Riego hymne national ${ }^{13}$, ce qui ne signifie pas (comme on trouve malheureusement trop souvent, en particulier sur internet) qu'il devint le premier hymne national de l'Espagne, mais seulement qu'il fut inclus dans la liste des chants de marche officiels de l'armée.

Il est coutume de dire que c'est l'enthousiasme des soldats à entonner cet hymne qui en assura la rapide diffusion par toute l'Espagne. Certes, mais à ceci près : la troupe ne choisissait pas à son gré le morceau qu'elle souhaitait entonner. Il n'aurait plus manqué que cela! C'était l'officier ou le sous-officier en tête de colonne qui l'imposait, souvent d'ailleurs, en fonction de la difficulté du terrain, parmi un certain nombre de chants dont l'apprentissage faisait partie intégrante de la formation militaire de base pour l'infanterie. Autrement dit, Riego n'a peut-être pas imposé à ses soldats de marquer le pas en chantant ses louanges, mais sa modestie n'a pas été telle qu'il crut devoir s'y opposer et on peut même le soupçonner d'avoir mis quelque complaisance dans son acceptation.

On le peut d'autant plus que Riego s'adonna également au culte de sa propre personnalité avec le fameux Trágala, perro. Il faut convenir avec Alcalá Galiano ${ }^{14}$ que ce ne fut qu'une chanson grivoise d'une rare médiocrité; il n'en fut pas moins présenté dans la presse (le Diario de Barcelona et La Abeja del Turia ${ }^{15}$ ) comme un "chant patriotique " qui, connut lui aussi un succès époustouflant et fut même l'objet de parodies ${ }^{16}$. Quand, après son arrestation en 1823, les serviles purent épancher leur bile contre Riego, ils l'accusèrent d'en avoir été l'auteur ${ }^{17}$. C'est faux. Mais c'est bien dans son entourage proche qu'il faut chercher le premier parolier de ce cri de guerre des exaltés. En fait, c'était un autre hymne à Riego : tout au long des quatre années du Triennat libéral, son texte a connu de multiples variantes ${ }^{18}$. Il n'y eut (sauf pour le refrain, bien évidemment) qu'une seule invariable : l'introduction :

Los milicianos

Y madrileños

La bien venida

La dan a Riego.

12 Aussi, quand le 3 septembre 1820, au théâtre de la Cruz, à Madrid, le chef politique de Madrid tenta d'interdire à Riego d'entonner le Trágala comme le demandait le public, (qu'on avait déjà régalé de l'Hymne de Riego), il s'opposa moins à l'interprétation d'un chant révolutionnaire qu'à un exercice d'auto-célébration du héros de la chanson. Et évidemment, son attitude fut fort significative des craintes que pouvait susciter ce que ses adversaires qualifieront de suffisance de Riego.

13 Mais l'entourage de Riego n'était pas le seul à chanter ses louanges. Les poèmes qui furent composés en son honneur le furent sur l'ensemble du territoire espagnol (Madrid, bien sûr, mais aussi Algeciras, Antequera, Barbastro, la Corogne, Elorraige (Vitoria) Mérida, Murcie, Oviedo, Saint-Jacques de Compostelle) et (par deux fois) à Londres, par des résidants espagnols ${ }^{19}$. Il y eut même un jeune Français qui composa dans sa langue une épître qui fut publiée à Madrid en $1820^{20}$. Certes, dans un certain nombre de cas - un peu plus d'un tiers- il partageait la vedette avec ses compagnons d'armes (Quiroga, Arco-Agüero, López Baños). Mais ce fut à lui seul que l'on dédia des recueils contenant des poèmes qui pouvaient encenser tel ou tel de ses rivaux dans la gloire, comme celui que publia à Valence en 1823 le citoyen et imprimeur Mariano de Cabrerizo sous le titre de Colección de canciones patrióticas que dedica al ciudadano Rafael del Riego y a los valientes que han seguido sus huellas. Dans l'enthousiasme de leurs 
louanges, nos poètes - adulateurs ne tardèrent guère à accoler au nom de Riego un certain nombre de qualificatifs homériques qui collèrent si bien à sa personne que l'auteur anonyme d'une composition publiée dans le Diario de Madrid du 24 octobre 1823, après l'arrestation et transfert à Madrid de celui qui, le $1^{\text {er }}$ janvier 1820, avait proclamé le rétablissement de la Constitution de 1812, n'hésita pas à les reprendre et intituler son pamphlet :

Décimas en honor y gloria del primer héroe

de la libertad española, el invicto, el grande e inmortal

D. Rafael del Riego, \&c., \& $c^{21}$.

14 Présenté comme un nouveau Cid, ou un nouveau Padilla, la gloire put bien enivrer Riego. Dès qu'ils purent compter sur les baïonnettes du duc d'Angoulême pour imposer leurs idées, les serviles ne manquèrent pas de lui faire grief de son orgueil et ambition. Mais dès 1821 (sans que malheureusement on puisse préciser la date), on trouve dans un dizain publié dans le numéro 4 du Látigo liberal contra $E l$ Zurriago indiscreto, revue d'un libéralisme fort modéré, une dénonciation de l'amour propre excessif (entendez orgueil démesuré) de Riego

El amor propio es muy ciego

y así como echó un manchón

en el gran Napoleón,

lo ha querido echar en Riego;

exaltado como el fuego

se ha podido equivocar

y acaso, acaso, pensar

que todo el pueblo español

le reconoce por Sol

del suelo peninsular ${ }^{22}$.

Les « enfants de Riego » (une expression que l'on trouve, par exemple, dans un poème publié dans la vingt-quatrième livraison du Zurriago, parue en janvier $1822^{23}$ ) n'en perdirent pas pour autant leur enthousiasme et ne cessèrent de dénoncer la volonté du gouvernement d'interdire le cri jugé séditieux de «viva Riego!», comme on peut voir dans ce fragment d'une composition publiée en février 1822 dans le numéro 26 du même Zurriago :

Riego es el restaurador

De la española grandeza.

El querernos obligar

Por terribles anatemas

A no decir viva Riego

Viva el padre de la Iberia

Es lo mismo, para el caso,

Que acostarse con su abuela ${ }^{24}$.

16 C'est sans doute la formulation la plus pittoresque de la revendication du droit à acclamer Riego. Mais ce n'est pas la seule. Toutefois, seuls les journaux «exaltés » publièrent désormais des poèmes en hommage au héros de las Cabezas. Riego, unanimement reconnu par les libéraux comme un héros en 1820, fut désormais un personnage "clivant », comme disent nos journalistes et politologues et Riego ne fut plus que le chef (le caudillo) des descamisados. On le savait déjà. Mais l'étude des poèmes composés en son honneur permet de fixer un terminus a quo au phénomène. Par 
ailleurs, la présence ou non de ces couronnes poétiques dans leurs feuilles permet de classer idéologiquement un certain nombre de journaux sur lesquels Alberto Gil Novales ne s'est pas prononcé et, par exemple, de ranger parmi les exaltés El Chismoso, de Murcie, ou El Mensajero, de Séville. Enfin, on observera non sans intérêt que deux périodiques rivalisèrent dans la publication d'hommages poétiques à Riego: $E l$ Espectador, organe du Grand Orient d'Espagne (qui en publia neuf entre mai 1821 et le premier janvier 1823) et El Zurriago, soutien des comuneros qui, bien que (selon sa propre expression) Riego " n'eut pas tout à fait ses papiers en règle de ce côté-là ${ }^{25}$ en publia 14 entre septembre 1821 et mai 1822. Cela semble indiquer qu'au moins au tour de la personnalité de Riego, une «alliance objective » entre modérés et exaltés était possible, comme en témoigne la composition intitulée « Padilla y Riego. Himno patriótico de unión " publiée dans le numéro 4 (7 février 1823) de l'Apéndice al Zurriago ${ }^{26}$. Mais, évidemment, c'est un point qui mériterait d'être creusé et une théorie qu'il conviendrait d'étayer par d'autres faits.

\section{Le retour de l'absolutisme}

Nous ne connaissons pas de composition poétique en l'honneur de Riego postérieure à cette date du 7 février 1823 et si cette année-là le citoyen libraire-imprimeur valencien Mariano de Cabrerizo publia sa Colección de canciones patrióticas que dedica al ciudadano Rafael del Riego y a los valientes que han seguido sus huellas, nous ignorons à quelle la date exactement. En revanche, le 31 mai, El procurador general del Rey donna le la et publia des séguedilles qu'accompagnées de tambourins et de guitares devraient chanter les Manolas le jour du rétablissement de "l'antique et légitime gouvernement du Roi Ferdinand VII, notre seigneur, que Dieu ait en sa sainte garde ». En fait, c'était un appel au lynchage de ceux qui avaient entrâné l'Espagne dans le libéralisme ; Riego, Lopez Baños et Quiroga :

Quiroga, López-Baños,

Riego y Agüero

Son los cuatro ladrones

Que nos perdieron:

Y su heroísmo

Fue solo cobardía,

No patriotismo.

Así como Arco-Agüero

Murió arrastrado

Razón será que Riego

Muera colgado:

Y que a la hora

Le siga López-Baños,

Después Quiroga ${ }^{27}$.

Le même périodique publia, les 17 juin et 19 juillet, deux autres "chants patriotiques royalistes" dans lesquels étaient dénoncées les "exactions » de Riego. Il s'abstint toutefois de participer à la curée quand, après avoir été capturé à Arquillos, Riego fut transféré à Madrid pour y être jugé. C'est le Diario de Madrid qui prit le relai en publiant, le 16 septembre 1823, une « octava a la pasión del caudillo de los jacobinos españoles el cabecilla Riego » que suivirent quatre autres pièces (les 9, 23, 24 et 29 octobre 1823), 
dans lesquelles, sans la moindre pitié, on insultait le vaincu et réclamait contre lui qu'il fut non seulement condamné à mort, mais que son cadavre fût dépecé. Tous ces poèmes furent publiés soit de façon anonyme, soit en étant signés uniquement des initiales de leurs auteurs. Mais il y eut quand même un individu, D. Diego Antonio Coelo de Portugal, «Caballero Maestrante de la Real de Ronda y Socio de número de esta Real sociedad y de la de Granada ", pour exhiber fièrement son nom en tête du chant qu'il publia (à ses frais) pour rendre grâce au Seigneur d'avoir empêché Riego de s'emparer du trésor de la capitale de Jaén... et se faire quelque mérite de son « bon esprit $»^{28}$.

L'intérêt de ces poèmes réside d'abord dans la liste des crimes dont on veut persuader l'opinion publique qu'ils ont été commis par Riego : avoir insulté le roi et la religion ; avoir été un despote ; un assassin, un franc-maçon, un jacobin, un anarchiste, un voleur qui avait dépouillé les «bons sujets" de leurs emplois au profit des siens; un lâche, avoir trahi son roi et sa patrie, notamment en empêchant l'expédition militaire de partir pour l'Amérique; avoir imposé le chant du Trágala dont il était l'auteur ; s'être pris pour l'empereur des Espagnols et s'être fait acclamer sous le nom de Rafael I ${ }^{\text {er }}$; avoir exigé d'énormes contributions des populations et des communautés religieuses; être un libertin et enfin un parjure qui n'avait pas respecté les clauses des cessez-le feu conclus avec des généraux royalistes. Les Espagnols qui, en 1820, avaient paré Riego de toutes les vertus, furent-ils convaincus, en 1823, qu'il était coupable de tant de méfaits? Ce n'est pas exclu et, d'Arquillos à Madrid, et en particulier à Andujar, Riego lui-même avait eu l'occasion de constater la versatilité des foules.

En revanche, nous n'avons retrouvé aucun poème relatant l'exécution de Riego et (semble-t-il) aux injures succéda le plus profond silence. C'est d'autant plus surprenant que le principal organe de l'absolutisme politique et religieux rétabli, El Restaurador, s'attacha, avec l'accord du pouvoir, à accréditer dans l'opinion que Riego avait fait une «bonne mort », une mort chrétienne et avait racheté ses " crimes » par l'intensité et la sincérité de la contrition ${ }^{29}$. Si l'on admet comme axiome que «la prose s'envole; les vers restent", cela méritait bien un poème sans doute. Mais, dans les sphères de l'absolutisme rétabli, on dut décider de ne pas accorder cette nouvelle gloire à Riego dont on ne voulut faire ni un modèle de repentance ni un martyr.

21 Ce rapide survol de l'analyse de la figure de Riego dans la poésie du Triennat libéral nous confirme, nous semble-t-il, dans l'idée que l'étude systématique de ce genre littéraire serait de nature à nous éclairer sur la véritable nature de cette opinion publique qui fut tout l'enjeu de la seconde Révolution d'Espagne, aussi bien lorsqu'elle put s'exprimer librement que lorsque l'absolutisme et le despotisme s'arrogèrent à nouveau l'exclusivité du droit d'expression. Un travail d'ensemble qui embrasserait, à la fois, les principaux acteurs de la révolution de 1820 et les événements les plus significatifs du Triennat libéral (comme l'abolition du Saint-Office de l'Inquisition) serait sans doute du plus grand intérêt. Aurons-nous le temps de le mener à bien? Comme disait Jacques Brel, « si ce n'est pas certain, c'est quand même peut-être ».

Il existe plusieurs variantes du Trágala qui ont été étudiées par Emilio La Parra dans son article cité supra, note 18. Nous avons trouvé trois autres versions de cette chanson : El Trágala de los liberales a los pancistas, publiée par Tomás Segara dans son recueil de poésies populaires (Poesías populares colegidas por Don Tomás Segara español nativo, profesor de su lengua materna en el Real instituto el Maximilianeum y lector de la universidad de Munique (Baviera), Leipzig, F. A. Brockhaus, 1862, p. 90-91) ; El nuevo Trágala del Palo, el Verdugo y el Martillo, qui parut dans le Diario constitucional, político y mercantil de Barcelona 
du 16 septembre 1821, p. 3, et une parodie d'inspiration «servile » dont El Zurriago ne cita que le refrain dans son $n^{\circ} 10$ ( novembre 1821) à la rubrique « Noticias de Madrid» en précisant qu'elle avait été chantée rue de Toledo, dans la nuit du 29 octobre précédent par six hommes qui avaient été interrompus par l'intervention de la milice. I - EL TRÁGALA DE LOS LIBERALES A LOS PANCISTAS

CORO

Tú que no quieres

lo que queremos,

la ley preciosa

do está el bien nuestro:

trágala, trágala

trágala, perro.

SOLO

Ya no te engañe

tu mal deseo.....

que en mil visiones

te trae inquieto.

CORO

Trágala, trágala etc.

SOLO

¡O ley de vida

para los buenos!

que ya no sufres

en nuestro suelo

Ni casa negra,

ni jueces negros,

ni el absoluto

bárbaro cetro.

CORO

trágala, trágala etc.

SOLO

Busca otros hombres,

otro hemisferio:

busca, cuitado:

déjanos quietos. 
Donde, no sabe

que a voz en cuello,

lo que vivieres,

te cantaremos.

CORO

trágala, trágala etc.

SOLO

Dicen que el trágala

es insultante;

pero no insulta

sino al tunante.

Y mientras dure

esta canalla,

no cesaremos

de decir trágala.

CORO

trágala, trágala etc.

II - EL NUEVO TRÁGALA

Del Palo, el Verdugo y el Martillo

Muchos con capa

de liberales

lorden [sic] alteran,

viles e infames;

nada consiguen,

pero ellos prueban

por todos lados

a ver si pega.

CORO

Trágala, trágala

Vil servilón,

Y el Palo haga

Su obligación.

Hay muchos que entran

en la Fontana, 
con el deseo

de ver si se arma

una de aquellas

que ellos desean;

¡pero infelices,

En vano siembran!

Trágala \&c.

Los liberales

nos esforzamos;

y los serviles,

viles insanos,

roban correos,

y les dan la muerte,

y es porque el Palo

no anda corriente.

Trágala \&c.

Si el Palo siempre

puesto estuviera,

y la justicia

derecha anduviera,

no matarían los Postillones,

ni en Madrid hubiera

tantos ladrones.

Trágala \&c.

El Palo rija,

el Verdugo apriete,

y este es el modo

que ande corriente.

Nuestro sistema

siempre adelante,

y en España queda

Nación triunfante.

Trágala \&c.

Porque a un faccioso 
que se ha encontrado

en un delito

tan declarado,

se echa a la calle

por los talegos;

y si esto es cierto

¿qué es lo que haremos?

Trágala \&c.

¿Qué hace el Verdugo

siempre parado,

teniendo España

tanto malvado?

El hombre, el niño,

Mujer y niña,

Dicen que el miedo

Guarda la viña.

Trágala \&c.

Si los serviles

no ven castigo,

todos los días

harán lo mismo;

y castigando

severamente

se hará modesto

el insolente.

Trágala \&c.

¿Queréis se limpie

pronto la corte

de los bribones?

es el resorte

poner seis palos

en la plazuela,

y el juez sentencie, 
y no se conduela.

Trágala \&c.

¡Si vemos reos

que ha perdonado

que no pagaban descuartizados!

¿Cómo queremos

vernos tranquilos

si así se aumentan

los enemigos?

Trágala \&c.

En vano fundan

ya los serviles

sus esperanzas

bajas y viles;

porque los Rusos

ya acá no vienen

porque en el Turco

gran guerra tienen.

Trágala \&c.

De los serviles

y de gente perra

será el azote

Inglaterra;

y los que quieran

curar sus males

sigan en tiempo

a los liberales.

Trágala \&c.

Solo un recurso

tenéis, pacistas;

dejar en tiempo

vuestras conquistas;

haceros fieles 
a la Nación

y decir venga

Constitución.

Trágala \&c.

Tres defensores

tiene la España,

justos y netos,

sin más patraña:

Palo y Verdugo

y el Martillito

que en precisando,

está prontito.

Trágala \&c.

II

Trágala, trágala

Tu liberal

Tu que no quieres

Corona real.

\section{ANNEXES}

APPENDICE

\section{NOTES}

1. Gérard Dufour, Sermones revolucionarios del Trienio liberal, Alicante, Instituto de Cultura Juan GilAlbert, 1991.

2. «Roucouler la guerre, vociférer la paix : les événements d'Espagne de 1820 à 1823 dans les poèmes français publiés par la presse de l'époque ", El Argonauta español, n 13, 2016 ; http:// argonauta.revues.org/2311

3. Compendio de la predicación del P. Fr. Diego de Cádiz en la ciudad de Valencia en 1787, compuesto por el más amante, aunque el menos aprovechado de sus oyentes, en Valencia, en la imprenta de Salvador Faulí, junto al colegio del Corpus Cristi, donde se hallará, s. f., 24 p.

4. On ne compte pas moins de cinq versions versifiées de la Charte octroyée publiées en France entre 1820 et 1824 : Charte constitutionnelle donnée par S. M. Louis XVIII en 1814, mise en vers 
par un constitutionnel régulier, à Paris, chez l'éditeur, rue de Bièvre, $\mathrm{n}^{\circ} 32$ et chez les marchands de nouveautés, signalé dans la Bibliographie de la France ou Journal de l'imprimerie et de la librairie, année 1820, à Paris, chez Pillet aîné, imprimeur-libraire, éditeur de la collection des mœurs françaises, rue Christine, $n^{\circ} 5,11$ mars ( $\left.n^{\circ} 11\right)$, p. 132, n 809. Il est précisé que « l'éditeur est M. Pinot de Saint-Pierre "; Charte constitutionnelle en vers ; précédée d'une épître au roi, imprimerie de Herhan, Paris (Bibliographie de la France... 12 août (n 33), p. 441, n²909); Poème politique ou la Charte alexandrine par M. R Lacombe du Blanc (Berri), imprimerie de Poulet, à Paris, annoncé dans la Bibliographie de la France de 1820, 17 juin ( $\left.{ }^{\circ} 25\right)$, p. 328, $n^{\circ} 2251$, qui précise : "C'est la Charte mise en alexandrins »); La Charte constitutionnelle donnée par S. M. Louis XVIII l'an de grâce 1814 ; poème didactique dédié aux Français par Legendre (Louis Désiré), ancien sous-officier de hussards, imprimerie de Risler, à Mulhausen (Bibliographie de la France... du 2 décembre 1820 ( $n^{\circ} 49$ ), p. 673, $n^{\circ} 4397$, et La Charte constitutionnelle mise en vers, avec notes et variantes par L. H. d'H***, imprimerie de Didot, à Paris signalé dans la Bibliographie de la France... du 10 avril 1824, ( $\left.\mathrm{n}^{\circ} 15\right)$, p. 219, $\mathrm{n}^{\circ} 1816$.

5. Compendio de los más esenciales artículos de la Constitución española, en verso castellano, para uso de las escuelas de primeras letras, por un profesor de las mismas, ouvrage annoncé dans la Miscelánea de Comercio, Artes y Literatura du 16 janvier 1821, n 474, p. 4.

6. Lettres champenoises, ou Correspondance morale et littéraire rédigée par MM. De Feletz, Michaud, O'Mahony, Mely-Janin, Laurentine, Saint-Prosper et plusieurs autres hommes de lettres adressée à Mme de ${ }^{* * *}$, à Arcis-sur-Aube, Paris, chez Pillet aîné, imprimeur-libraire, éditeur de la Collection des mours françaises, rue Christine, $\mathrm{n}^{\circ} 5,61^{\mathrm{e}}$ lettre, tome VII, (1821), p. 199.

7. Alberto Gil Novales, Las sociedades patrióticas (1820-1823). Las libertades de expresión y de reunión en el origen de los partidos políticos, Madrid, Tecnos, 1975, 2 vols.

8. Zaragoza, Prensa de la Universiad de Zaragoza, 2019.

9. Miguel del Riego, canónigo de Oviedo, «A Rafael Riego. Oda», poème publié dans La principal parte del Romancero de Riego..., s. 1. [London], 1846, p. 21-24 avec la note suivante : «Esta Oda se formó en los primeros momentos de la convulsión cuando aún solo se conocía lo de Galicia; así no debe extrañarse su lenguaje porque no podía ser otro en otras circunstancias».

10. ¿Quién es el libertador de la España? Reflexiones para decidir esta cuestión expuestas por el capitán don Santiago Pérez, ayudante de campo del comandante general de la primera división del Ejército Nacional reunido en Andalucía, Sevilla, 1820. Cette publication fut traduite en français : Quel est le principal libérateur de l'Espagne? Réflexions sur cette question exposées par un ami de la vérité. Ouvrage traduit de l'espagnol, Paris, 1820. Toutefois, il fut précisé dans la Bibliographie de la France de novembre 1820 ( $\left.n^{\circ} 45\right)$, p. 611, $n^{\circ} 3969$, que cette édition n'était pas destinée à la vente.

11. On trouvera un excellent état de la question dans Victor Sánchez Martín, Rafael del Riego, símbolo de la revolución liberal, tesis doctoral, Universidad de Alicante, janvier 2016, p. 331-332.

12. $\mathrm{N}^{\circ} 315$, n.n. [p.4]

13. Gazeta de Madrid, 14 avril 1822, $\mathrm{n}^{\circ}$ 106, p. 564.

14. Memorias de un setentón, natural y vecino de Madrid escritas por Ramón de Mesonero Romanos, nueva ed., con notas y adiciones Madrid Oficinas de la Ilustración Española y Americana, I, p. 235-236: «La sociedad de la Fontana, que había tomado la iniciativa de esta semi-bufa solemnidad, le [a Riego] le obsequio después en sus mismos salones, y en seguida le condujo al teatro del Príncipe, donde, a vueltas de las más calumniosas aclamaciones, llegó a su colmo el desvanecimiento del héroe hasta entonar él y sus ayudantes su propio himno, cantado por todos los tonos y todas las disonancias posibles; hizo más, y fue disponer que sus ayudantes 
pusieran en conocimiento del público la insultante y grosera canción del Trágala, que traían de Cádiz y que tan perniciosa llegó a tener en la opinión de las masas populares, y por consiguiente , en la marcha violenta de la revolución».

15. La Abeja del Turia, 3 octobre $1820, n^{\circ} 53$, p. 198, qui précise qu'il s'agit d'un texte publié dans le Diario de Barcelona du 20 mars de la même année.

16. Cf. Infra, «Appendice».

17. D. Diego Antonio Coelo de Portugal, Caballero Maestrante de la Real de Ronda y Socio de número de esta Real sociedad y de la de Granada, La destrucción de Riego en el reino de Jaén. Poema. Canto único dedicado al divino Rostro de nuestro redentor Jesucristo que de tiempo inmemorial se venera en esta Santa Iglesia Catedral, por cuya mediación creemos piadosamente se ha obrado este gran prodigio, Jaén, por Don Manuel María de Doblas, Impresor de la Dignidad Episcopal, 1823, p. 5.

« Estas son las proezas

Del inventor del Trágala injurioso,

Que hizo al Código libre más odioso,

De aquel héroe inmortal de las Cabezas

De quien dijo el partido vocinglero

Que se juzgaba Pueblo soberano

Viva el Emperador Rafael primero,

Sustituyendo el cetro en un tirano ».

18. Cf. Emilio La Parra López, «La Canción del Trágala. Cultura popular en el inicio de la revolución liberal en España», La réception des cultures de masse et des cultures populaires en Espagne: XVIII'-XIXe siècles. Textes réunis par Serge Salaün et Françoise Etienvre, Paris, Les travaux du Crec, $\mathrm{n}^{\circ} 6$, mars 2009, http://crec-paris3.fr/wp-content/uploads/2011/07/actes-03-La-Parra.pdf .

19. El Español constitucional o Miscelánea de Política, Ciencias, Artes, Literatura, \&c., $n^{\circ}$ XXI (mai 1820), tome III, p. 399 et Miscelánea de Comercio, política y Literatura, 30 janvier 1821, $\mathrm{n}^{\circ} 327, \mathrm{p} 4$.

20. Épitre au Général Riego par un Jeune Français, Madrid, imprenta. de Repullés, 1820. Cité par Sánchez Martín (op. cit., p. 24), qui se réfère à I. Castells, La utopía insurreccional del liberalismo, Torrejos y las conspiraciones liberales de la década ominosa (Barcelona, Crítica, 1989), et reproduit quelques vers de ce poème. Celui-ci fut annoncé dans $E l$ Constitucional o sea Crónica científica, Literaria y político du 13 juillet 1820, n 431 [p. 4]: "Épitre au général Riego par un Jeune français, esto es, Epistola al general Riego por un francés joven, Madrid, por Repullés, y se pone en venta en las librerías de Oréa red de San Luis, Brun, frente de las gradas de San Felipe, y Hermoso, calle de la Guerguera. Esta composición satisfará sin duda a los aficionados a la poesía francesa. Debe ser además muy lisonjero para los españoles el entusiasmo con el que se celebra en otros países el heroísmo de los guerreros inmortales que nos han restituido nuestra libertad. El autor no olvida a su patria, y deplora con mucha energía los males que sufre actualmente ». Il faut toutefois observer que, contrairement à ce que laisse entendre El Constitucional et crut Sánchez Martín, ce texte ne fut jamais publié en France puisqu'il ne fut pas annoncé par la Bibliographie de la France et qu'il est plus qu'improbable qu'un imprimeur ait pris le risque d'en effectuer un tirage clandestin.

21. $\mathrm{N}^{\circ} 296$, p. 3.

22. $\mathrm{N}^{\circ} 4$, p. 7-8. 
23. P. 20 «En vano aterrarnos / Pretenden los siervos / Que nunca han temido / Los hijos de RIEGO ».

24. P. 13.

25. El Apéndice al Zurriago, 31 janvier 1823, n 3, p. 8: « ¡Viva Riego sin mandil! Repetiremos nosotros sin cesar, mal que le pese a la turba Masónica enemiga de los derechos del hombre en sociedad. Riego es propiedad de la patria; Riego no puede pertenecer a una sociedad cuyo nombre envilece el suyo; Riego no puede ser el instrumento de una facción temeraria y desorganizadora; Riego es hijo de Padilla aunque no tenga sus papeles en regla; Riego en fin es deudor a los comuneros de su existencia, pues que ellos fueron sus defensores acérrimos cuando se le perseguía y calumniaba por el ministerio de los Argüelles y Feliús y por muchos de los Masones que ahora lo vitorean, porque les conviene usar del nombre respetable de Riego para sus intrigas y tramas criminales ».

26. P. 13-16.

27. $\mathrm{N}^{\circ} 15, \mathrm{p} .78$.

28. La destrucción de Riego en el reino de Jaén. Poema. Canto único dedicado al divino Rostro de nuestro redentor Jesucristo que de tiempo inmemorial se venera en esta Santa Iglesia Catedral, por cuya mediación creemos piadosamente se ha obrado este gran prodigio, Jaén, por Don Manuel María de Doblas, Impresor de la Dignidad Episcopal, 1823. L'auteur publia également en 1823, chez le même imprimeur, un autre poème dans lequel il dénonça les « crimes » de Riego: El deseado regreso de las Personas Reales y su sentimiento de devoción al Santísimo ROSTRO de nuestro Redentor Jesuchristo que adoraron SS. MM. Reales en la Real Carolina. Poema en un canto, dedicado a nuestra virtuosa Reina Doña María Josefa Amalia de Sajonia.

29. El Restaurador, 6 novembre 1823, n 116, p. 1032: « Madrid 5 de noviembre [...] Hoy se ha intimado a D. Rafaël del Riego la sentencia de muerte, y a su consecuencia se le ha puesto en capilla. Desde este momento ya no inspira más que compasión ese desgraciado; y esperamos que todos los verdaderos realistas participarán en esta parte de los mismos sentimientos que El Restaurador, distinguiéndose hasta en esto de los feroces revolucionarios " et "Exposición que de su puño y letra escribió D. Rafaël del Riego la víspera de sufrir el último suplicio y del que por orden del Rey nuestro señor se ha sacado un fac simile", 14 décembre 1823, n 149 , p. 1295-1296. Cette version de la mort de Riego fut évidemment reprise par L'Ami de la Religion et du Roi, dans son numéro du 19 novembre 1823, n 968, tome XXXVIII, p. 41-42.

\section{RÉSUMÉS}

En 1820, avec le rétablissement de la Constitution de Cadix, la politique envahit tous les espaces, et notamment la poésie. Bon nombre des vers composés à cette période ont disparu. Mais ceux que l'on peut retrouver sont toutefois fort précieux pour juger de l'évolution de l'opinion publique qu'ils entendaient former et qu'en fait ils reflétaient. Les poèmes consacrés à Riego, qui en quatre ans passa du pinacle à l'échafaud, sont particulièrement significatifs de ce point de vue. Ils permettent de voir, notamment, comment l'entourage du général mit en place un très efficace système de communication qui lui valut très vite l'immense popularité qu'il connut tandis que, avant même le rétablissement de Ferdinand VII comme souverain absolu, en 1823, les serviles 
l'accusèrent de tous les crimes et exigèrent pour lui non seulement la peine capitale mais que son corps fut dépecé.

En 1820, con el restablecimiento de la Constitución de Cádiz, la política invade todos los espacios, y especialmente la poesía. Numerosos versos compuestos en aquella época han desaparecido. Pero los que podemos rastrear son sin embargo muy útiles para apreciar la evolución de la opinión pública que pretendían formar y de la que eran el reflejo. Los poemas consagrados a Riego, que en cuatro años pasó del pináculo al cadalso, son especialmente significativos desde este punto de vista. Permiten apreciar, entre otras cosas, cómo el entorno del general puso en marcha un sistema de comunicación sumamente eficaz que le permitió alcanzar rapidísimamente una inmensa popularidad, mientras que, en 1823, antes siquiera del restablecimiento de Fernando VII como soberano absoluto, los serviles le acusaron de todos los crímenes y exigieron para el él no solo la pena capital, sino que su cuerpo fuera descuartizado.

In 1820, with the Cadix Constitution being re-established, politics invaded all fields, including poetry. Many verses written then have since disappeared. But those that can be recovered have great value for understanding the evolution of a public opinion they intended to craft, and they in fact reflected. Poems dedicated to Riego, who in the course of four years fell from grace to the scaffold, are particularly meaningful from that point of view. They permit to see how the general's followers elaborated a highly efficient public relations system which quickly owned him the huge popularity he experimented whereas, even before the reestablishment of Ferdinand VII as an absolute monarch, in 1823, serviles charged him with all imaginable crimes, and called not only for him to be executed, but for his body to be skinned.

\section{INDEX}

Mots-clés : Rafael del Riego, poésie politique, Himno de Riego, Trágala

Palabras claves : Rafael del Riego, poesía política, Himno de Riego, Trágala

Keywords : Rafael del Riego, political poetry, Himno de Riego, Trágala

\section{AUTEUR}

\section{GÉRARD DUFOUR}

Aix-Marseille Univ, CNRS 7303, TELEMMe, Aix-en-Provence, France 